\title{
Extrato da folha do "murici" como inibidor da corrosão do aço carbono em meio ácido.
}

\author{
Marcelo Freire de Andrade Neto* (Graduando em Química na Universidade do Estado do Ceará - UECE) \\ Rafaella Silva Gomes (Graduanda em Química na Universidade do Estado do Ceará - UECE) \\ Mauro Filho Alves de Alencar (Graduando em Química na Universidade do Estado do Ceará - UECE) \\ Rubens Damigle Alves Marreira (Graduando em Física na Universidade do Estado do Ceará - UECE) \\ José Gilmar da Silva do Nascimento (Prof. Substituto na Universidade do Estado do Ceará - UECE) \\ *Email:marcelof_a@hotmail.com
}

\section{Resumo:}

Inibidores verdes são cada vez mais estudados com o intuito de reduzir o uso de compostos tóxicos utilizados em banhos de decapagem de metais em indústrias. Este estudo teve como objetivo verificar a eficiência inibitória (EI) do extrato orgânico obtido a partir das folhas de "murici" contra a corrosão na superfície do aço carbono em $\mathrm{HCl} 1 \mathrm{M}$. Realizou-se teste de imersão com perda de massa e utilizou-se técnicas eletroquímicas. A voltametria cíclica mostrou que a adição do extrato promove inibição catódica. A partir de curvas de polarização estimou-se a EI em 36 e 49\% para 260 e 1000 ppm-concentrações do extrato, respectivamente. Conclui-se que o extrato em questão é um satisfatório inibidor de corrosão do aço-carbono em HCl 1M.

\section{Palavras-chave:}

Extratos orgânicos; inibição catódica; corrosão.

Espaço reservado para organização do congresso. 


\section{I ntrodução}

Os inibidores de corrosão são substâncias químicas ou misturas de substâncias que adicionadas ao meio onde está exposto o metal, conseguem diminuir a velocidade da corrosão ou dissolução do metal [1]. Dentre os inibidores de corrosão, tem se destacado o uso dos inibidores orgânicos. Os inibidores orgânicos atuam formando um filme protetor na interface metal-meio corrosivo, cuja eficiência depende da qualidade do filme formado [2], o que torna de fundamental importância o conhecimento de propriedades físicas e químicas, como também, o mecanismo de ação dos inibidores e a natureza do meio e do metal a ser protegido [2-3].

Existem muitos estudos que apresentam compostos aminados e aminas como eficientes inibidores de corrosão de metais, utilizando-se desde aminas primárias a sais de amônio quaternários com cadeias hidrocarbônicas simples, ramificadas ou cíclicas, ou ainda, aromáticas, variando de 4 a mais de 8 átomos de carbono na cadeia [1-4].

Uma série de compostos orgânicos é conhecida por serem aplicáveis como inibidores de corrosão do aço em meios ácidos, como exemplo têm os coloides, sabões de metais pesados, substâncias orgânicas com heteroátomos, podendo-se citar os aldeídos, aminas e compostos heterocíclicos nitrogenados e ureia [4-5].

Esses compostos normalmente contêm nitrogênio, oxigênio ou enxofre em um sistema conjugado no qual suas moléculas, através de adsorção, aderem-se à superfície metálica, formando uma barreira ao ataque corrosivo [7-8]. Embora muitos desses compostos tenham alta eficiência de inibição, muitos são indesejáveis devido à sua toxicidade ao meio ambiente e seu alto custo [4].

Em vista disso, tem-se atualmente a busca por inibidores de corrosão que sejam baratos e não tóxicos, como por exemplos, os inibidores naturais, isto é, aqueles oriundos de plantas, representando meios de desenvolvimento sustentável e de inovação [9-10]. Podem ser citados como exemplos, extratos de plantas, onde estes apresentam diferentes compostos orgânicos (por exemplo, taninos, alcaloides, pigmentos, saponinas, carboidratos, proteínas e aminoácidos); alguns dos quais têm sido relatados possuir habilidade inibidora de corrosão [10].

Adicionalmente, são verificadas que muitas espécies vegetais apresentam grande potencial de compostos orgânicos, dentre estas a espécie do gênero Byrsonima. Esta planta é comumente empregada pela medicina tradicional como antiasmática, antitérmica e no tratamento de infecções de pele. Isto se deve ao fato que as plantas da família Malpighiaceae são ricas em substâncias antioxidantes como os taninos [9]. Sendo assim, é verificada que a região da Caatinga (predominantemente o semiárido brasileiro) apresenta grande diversidade floristica, destacando-se o uso de plantas típicas com grande potencial fotoquímico. Neste sentido, tem-se o gênero Byrsonima que é composto por cerca de 150 espécies, pertencente à família Malphigiaceae e este amplamente distribuído na América Central e do Sul. 
Por outro lado, o aço carbono é uma das ligas importantes de ferro, que tem numerosas aplicações industriais e de engenharia devido às suas excelentes propriedades mecânicas. Apesar disso, é muito suscetível à corrosão, devido à sua instabilidade termodinâmica, especialmente em meio ácido [11]. Portanto, o estudo de fenômenos de corrosão do aço carbono tornou-se importante, particularmente em meio ácido. Entre os ácidos, o ácido clorídrico $(\mathrm{HCl})$ é um dos agentes mais amplamente utilizados em várias indústrias para a remoção de filmes de óxido indesejáveis e de produtos de corrosão da superfície do aço [12] .

Para este efeito foi conduzido o ensaio de imersão com perda de massa, a análise por espectrofotometria de absorção atômica (EAA) e técnicas eletroquímicas. Também, foi realizada a análise da superfície da amostra de aço após o ensaio de imersão utilizando a técnica de microscopia eletrônica de varredura (MEV), associada à espectroscopia de análise da energia dispersiva por raiosX (EDX). Este trabalho tem como proposta investigar a eficiência de inibição da corrosão do aço carbono em ácido clorídrico na presença do extrato da planta Byrsonima sericea, vulgarmente denominada de "murici-da-praia”, nas concentrações de 260 e 1000 ppm.

\section{Procedimento Experimental}

\subsection{Preparação dos eletrodos}

Foi utilizado eletrodo de trabalho aço-carbono (aço carbono 1040) na forma de disco de, aproximadamente, $0,78 \mathrm{~cm}^{2}$ de área geométrica exposta foi submetida ao polimento mecânico em lixas de granulometria 180, 220, 360 e 1200, consecutivamente. Depois lavada com água destilada e, então, imersa em banho ultrassônico durante $5 \mathrm{~min}$, a fim de eliminar sujidades. Seguidamente, foi secada cuidadosamente, tendo-se uma das faces isoladas com material inerte. Este procedimento foi adotado para a realização do ensaio de imersão com perda de massa. Uma placa fina de platina soldada a uma haste de cobre embutida em resina epóxi em tubo de vidro constituía o eletrodo auxiliar. O eletrodo de referência era o $\mathrm{Ag} / \mathrm{AgCl}, \mathrm{KCl}_{\text {(sat), }}$ aferido a $25^{\circ} \mathrm{C}$.

\subsection{Preparação do extrato do "murici"}

As folhas do "murici” foram recolhidas no Campus do Itaperi da Universidade Estadual do Ceará (UECE), em Fortaleza - CE, armazenadas e secas, posteriormente imersas em álcool etílico 90\%. Após 7 dias, a mistura foi filtrada e o liquido sobrenadante colocado em retroevaporador para separar a fase do extrato e recuperar o solvente utilizado. Para a evaporação completa do solvente, a mistura foi colocada em banho-maria. 


\subsection{Preparação da solução de trabalho}

A fim de obter a solução ácida com 260 ppm de extrato, foram medidas 0,5 g do extrato e adicionado $30 \mathrm{~mL}$ de $\mathrm{HCl}$ concentração $1 \mathrm{M}$ (previamente preparada e padronizada). A solução foi misturada; não havendo diluição completa, a mesma foi submetida ao banho ultrassônico por 2 h e 30 min, acrescentando-se $6 \mathrm{~mL}$ de álcool etílico. Misturou-se $30 \mathrm{~mL}$ de solução com $470 \mathrm{~mL}$ de $\mathrm{HCl} 1$ $\mathrm{M}$, sob vigorosa agitação e aquecimento $\left(30^{\circ} \mathrm{C}\right)$ durante $10 \mathrm{~min}$. Para a concentração de $1000 \mathrm{ppm}$ na solução ácida, foram medidas $1,5 \mathrm{~g}$ de extrato para as quais foram acrescentados $5 \mathrm{~mL}$ de etanol e colocou-se a mistura em banho ultrassônico por 1 hora. Findo este período, foi adicionado 1 L de solução HCl 1 M.

\subsection{Descrições dos Ensaios}

O ensaio de imersão foi realizado a temperatura ambiente $\left(\sim 25^{\circ} \mathrm{C}\right)$. Uma das faces da amostra do metal foi isolada por material adesivo inerte, expondo a outra face ao ataque ácido. Findado o tempo de imersão pré-estabelecido $(0,5 ; 1 ; 4 ; 10 ; 15$ e 24 h), a amostra foi secada e, imediatamente, submetida à medição de sua massa, assim, possibilitando estimar a perda de massa sofrida em função do tempo de imersão. Portanto, foi determinado o valor da taxa de corrosão da amostra de aço carbono na solução ácida e, consequentemente, foi determinada a eficiência de inibição de corrosão.

Após o ensaio de imersão, foi retirada alíquota de $5 \mathrm{~mL}$ da solução. A partir desta técnica, foi realizada a determinação de concentração de íons Fe total em solução, usando o espectrômetro da Varian, modelo Spectraa 55, disponível no Laboratório de Química Analítica e Química ambiental (LAQAM), da UECE. Com os valores obtidos (em ppm), pôde-se calcular a massa de íons Fe em solução após o experimento de imersão.

Para polarização potenciodinâmica usou-se velocidade de varredura de potencial de $1 \mathrm{mV} \cdot \mathrm{s}^{-1}$; o potencial foi varrido de $-1 \mathrm{~V}$ a $+1 \mathrm{~V}$, para observar o potencial de corrosão tanto na ausência como na presença do extrato na solução, a temperatura ambiente $\left(\sim 25^{\circ} \mathrm{C}\right)$, utilizando o potenciostato MQGP-01, da Microquímica. A partir dos valores de corrente de corrosão foi possível estimar a EI do extrato.

O uso em conjunto das técnicas de MEV e EDX foi de grande importância na caracterização da superfície do aço corroída. Após o ensaio de imersão de 24 h na ausência e na presença, a amostra de aço-carbono foi devidamente acondicionada e encaminhada para análise. Para este fim, foi utilizado o microscópio eletrônico de varredura, Philips, modelo XL-30, tendo-se câmara acoplada para a análise por EDX, disponível no Laboratório de Caracterização de Materiais (LACAM) da Universidade Federal do Ceará. 


\section{Resultados e discussão}

A partir dos ensaios realizados e das técnicas efetuadas para o estudo proposto, têm-se os resultados que seguem discutidos.

\subsection{Estudo fitoquímico}

Por análise fitoquímica, o extrato da planta do gênero Byrsonima apresenta os seguintes compostos: taninos catequéticos, flavonoides e saponina; sendo identificada a presença de esteroide, triterpenóides (alfa e beta amirina, lupeol e ácido betulínico). Estes compostos foram identificados por Aguiar et al.[14], a partir do extrato clorofórmico de Byrsonima microphylla e do extrato das folhas de B. sericea, respectivamente.

\subsection{Perda de massa}

O gráfico 1 exibe a variação da perda de massa do aço-carbono em solução ácida na presença e na ausência do extrato etanólico Bysonima sericea. E, a partir do gráfico, foram determinados os valores da taxa de corrosão: 0,0075, 0,0047 e 0,0046 $\mathrm{mg} / \mathrm{cm}^{2} \mathrm{~h}$, para na ausência e na presença do extrato em 260 e 1000 ppm, respectivamente. Foi observado que, na ausência do extrato, o perfil é acentuado ao se comparar com o perfil denotado quando na presença do extrato. Os perfis evidenciados demonstram que o processo corrosivo na superfície do aço-carbono ocorre, porém, é minimizado na presença do extrato.

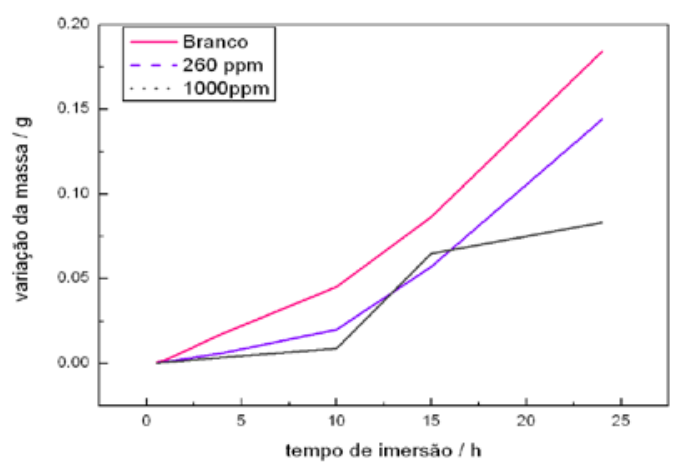

Gráfico1: Variação da perda de massa do aço carbono em HCl 1M com o tempo de imersão.

Portanto, foi encontrado o valor de 36 e 38\% de eficiência inibitória do processo corrosivo na superfície do aço carbono para as concentrações de 260 e 1000 ppm, respectivamente. Este fato indica que o extrato tem efeito de um inibidor razoável. Por outro lado, a partir da técnica de EAA, foi encontrado o valor de 28,24\% de eficiência inibitória para a concentração de 260 ppm. 


\subsection{Curva de polarização}

O Gráfico 2 exibe as curvas de polarização obtidas na ausência e na presença do extrato.

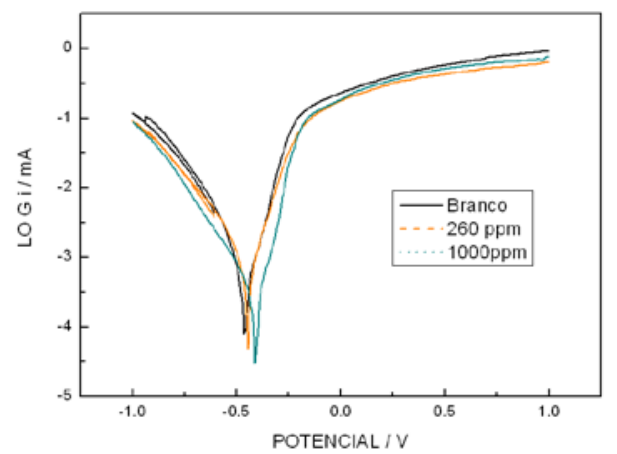

Gráfico 2 - Comportamento anódica e catódica do aço carbono na presença e ausência do extrato.

O potencial de corrosão $\left(\mathrm{E}_{\text {corr }}\right)$ apresentou deslocamento pouco significativo em relação àquele verificado na ausência do extrato (-0,465 V), com valores -0,447 e -0,414 V nas concentrações de 260 e 1000 ppm, respectivamente. Foi observado também que a corrente de corrosão (i $i_{\text {corr }}$ ), no gráfico em logaritmo vesus potencial, é aumentada na direção para valores de potenciais mais positivos, obtendose os valores de 0,0124, 0,0074 e 0,0042 mA (valores convertidos de LOGi/mA, mostrado no Gráfico 2), para amostra sem extrato, e para amostras nas concentrações de 260 e 1000 ppm com extrato, respectivamente. Estes parâmetros permitem sugerir que o extrato diminui a velocidade da corrosão do aço. Tendo o valor de eficiência de 40\% e 60\% para a concentração de 260 e 1000 ppm, respectivamente.

\subsection{Voltametria cíclica}

Foram obtidos voltamogramas em que o potencial foi varrido na faixa de potencial de -0,5 a $0,3 \mathrm{~V}$, variando-se a temperatura. O $\mathrm{E}_{\text {corr }}$ aumenta com o aumento da temperatura. Entretanto, foi observado que a adição do extrato promove a diminuição da corrente na região catódica e, praticamente, não varia com a ciclagem da varredura. E, por outro lado, com o aumento da temperatura, o $\mathrm{E}_{\text {corr }}$ diminue à medida que aumenta o número de ciclos de varredura na faixa de potencial verificada. Este fato sugere que a adsorção do extrato sobre a superfície do aço está sendo desfavorecida; admitindo-se que o extrato atue por mecanismo de adsorção, visto que, como revelado pelos testes fitoquímicos, os compostos tripertenóides e saponinas que, na literatura [14] são considerados como de caráter antioxidante, podem ser estes os responsáveis pela eficiência de inibição do extrato na corrosão do aço carbono. 


\subsection{MEV e EDX}

É observada pronunciada formação de crostas sobre a superfície do aço-carbono após o tempo de imersão de 24 h em HCl 1 M na ausência do extrato (Figura 3(a)). Estas crostas são, provavelmente, produtos de corrosão que se assemelham a óxidos de ferro. Por outro lado, o espectro da superfície evidencia picos de alta intensidade associados ao elemento $\mathrm{Fe}$ e um pico do elemento $\mathrm{Cl}$; este último proveniente da solução ácida (Figura 3(b)).
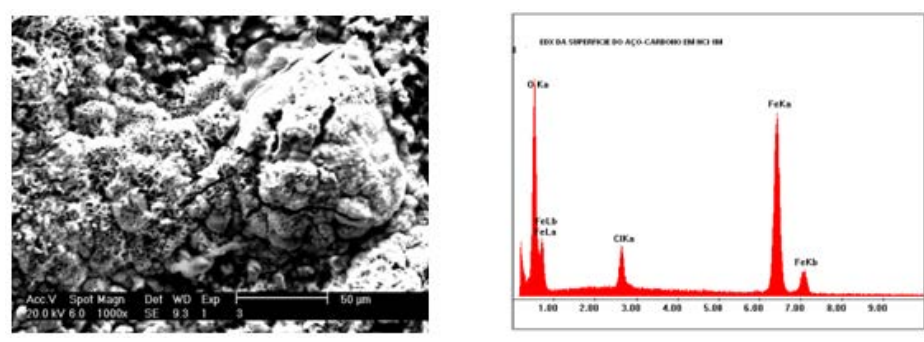

Figura 3 : (a) Imagem micrográfica e (b) espectro da superficie do aço em HCl 1 M na ausência do inibidor após o tempo de imersão de $24 \mathrm{~h}$

As imagens micrográficas mostram a formação de produtos de corrosão sobre a superfície do aço. A Figura 5(a) revela o aspecto morfológico da superfície do aço na presença do extrato (1000 ppm). É notada a intensa formação de produtos de corrosão. Na Figura 5(b), o espectro apresenta pico do elemento $\mathrm{O}$, picos do elemento Fe; sugerindo a formação de óxidos de ferro como produto de corrosão. A Figura 6(a) exibe a superfície do aço na presença do extrato (1000 ppm). É denotada a formação de produtos de corrosão; porém, estes se diferenciam em forma daqueles observados na ausência e na presença do extrato (260 ppm), figura 4. Na Figura 6(b), o espectro apresenta é similar aquele observado na Figura 5(b).

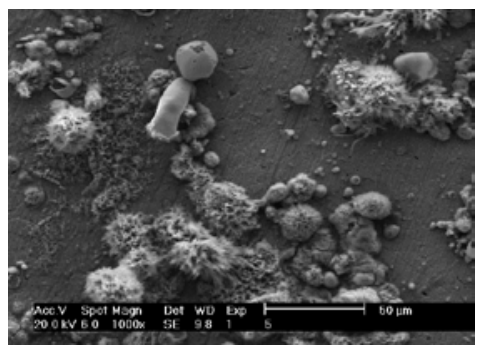

Figura 4 : Imagem micrográfica da superfície do aço na presença do extrato (260ppm).
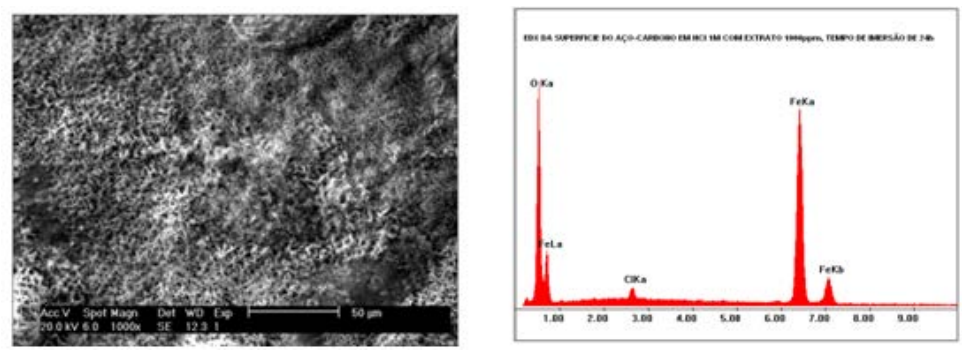
Figura 5 : (a) Imagem micrográfica e (b) espectro da superficie do aço em $\mathrm{HCl} 1 \mathrm{M}$ na presença do extrato (1000 ppm) após o tempo de imersão de 24 h
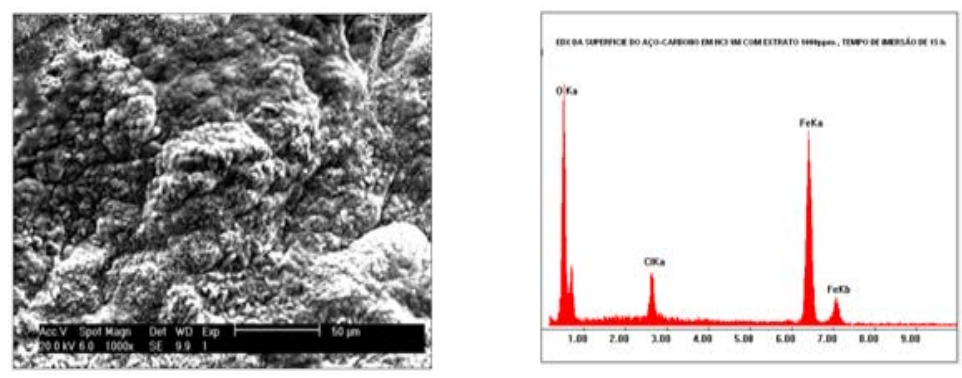

Figura 6 : (a) Imagem micrográfica e (b) espectro da superficie do aço em $\mathrm{HCl} 1 \mathrm{M}$ na presença do extrato (1000 ppm) após o tempo de imersão de 24 h.

\section{Conclusão}

Os resultados obtidos evidenciam que o extrato do "murici” é um razoável inibidor de corrosão do aço-carbono em $\mathrm{HCl} 1 \mathrm{M}$. Arbitrariamente, é colocado que um eficiente inibidor de corrosão deve apresentar EI acima de 70\% [6]. Para os testes realizados com a solução de extrato com $\mathrm{HCl} 1 \mathrm{M}$ foram identificados os compostos tripertenóides e saponinas. Tendo eficiência de inibição igual a 36 e $49 \%$, em termos de perda de massa, e 28\% em termos de íons Fe em solução, para a concentração de 260 ppm. A partir dos ensaios eletroquímicos, tem-se EI de 40 e 60\% para a concentração de 260 e 1000 ppm, respectivamente. As imagens micrográficas revelam que houve a formação de produtos de corrosão sobre a superfície; entretanto, menos acentuada quando na presença do extrato. Provavelmente, o extrato age marcadamente por mecanismo de adsorção; embora seja verificada a sua influência na reação catódica ocorrendo sobre a superfície do aço.

\section{Leaves extract of "murici” as corrosion inhibitor for carbon steel into acid.}

Abstract: Green inhibitors are increasingly studied with the aim of reducing the use of toxic compounds used in pickling baths in the industry. This study aimed to determine the inhibitory efficiency (IE) of the organic extract obtained from the leaves of "murici" corrosion on carbon steel surface in $\mathrm{HCl} 1 \mathrm{M}$. It was performed immersion with bulk loss test and electrochemical techniques are used. Cyclic voltammetry showed that the addition of the extract promotes cathodic inhibition. From the polarization curves, the IE was estimated at 36 and $49 \%$ for 260 and 1000 ppmconcentrations of the extract, respectively. It is concluded that the extract in question is a satisfactory corrosion inhibitor to carbon steel in $\mathrm{HCl} 1 \mathrm{M}$.

Keywords: Organic extracts; cathodic inhibition; corrosion. 


\section{Referências bibliográficas}

1. GENTIL, V.. Corrosão, LTC Livro Técnico e Cientificos S.A., 6ª edição, cap. 19-23, Rio de Janeiro: 2011.

2. FERNANDES, Y. T. e NETO, A. O. W.. NOVO INIBIDOR DE CORROSÃO PARA APLICAÇÃO EM OLEODUTOS, Instituto Brasileiro de Petróleo e Gás - IBP, 2004.

3. OGUZIE, E. E.. Corrosion inhibition of mild steel in hydrochloric acid solution by methylene blue dye, Materials Letters, V. 59, nº 8-9, p. 1076, 2005.

4. PEREIRA, F.D. Avaliação de aminas como inibidores de corrosão para aço carbono e aços inoxidáveis, Sheila Pressentin Cardoso*, Corrosion Acta, v.42, n 3, p. 455, 1997.

5. SASTRI, V.S. Corrosion Inhibitors, Principles and Applications, 8ª edição, cap. 3- 6, 2001.

6. BOSCOLO, O. H.. Potencial antioxidante de algumas plantas de restingas citadas como medicinais. Revista Brasileira de Plantas Medicinais, nº 5, p. 8-12, 2007.

7. GOTTLIEB, O. R. Quimiossistemáica como ferramenta na busca de substâncias ativas. Farmacognosia: da planta ao medicamento. Porto Alegre/Florianópolis: UFRGS/UFSC, 5aㅜ edição, p. 91-105, 2004.

8. OKAFOR, P. C. Green Inhibitors for Corrosion Protection of Metals and Alloys: An Overview, Bulletin of Electrochemistry, nº 8, p. 347-352, 2005.

9. RODRIGUES, P. A.. Atividade gastro-protetora e antioxidante de extratos e constituintes químicos de Byrsonima sericea DC. e Plectranthus grandis cramer (Willensem). Dissertação de Mestrado em Ciências Veterinárias, Universidade Estadual do Ceará, N. de paginas: 146.: 2008.

10. GOMES, J.A.C., Obtenção de inibidores de corrosão a partir de extratos de produtos naturais, PEMM-COPPE-UFRJ. CP 68505, 21941-972, Rio de Janeiro, RJ. 2010. 
11. OBI-EGBEDI, N. O.. Adsorption behavior and corrosion inhibitive potential of Xanthene on mild steel/ sulphuric acid interface. Arabian Journal of Chemistry, V. 01, nº 5.: 2012.

12. LEBRINI, M., F. ROBERT, F.. Corrosion inhibition of C38 steel in 1 M hydrochloric acid medium by alkaloids extract from Oxandra asbeckii plant. Corrosion Science, n 5.: 2011.

13. AGUIAR, R. M.; DAVID, J. P.; DAVID, J. M.. Unusual naphtoquinones, catechin and triterpene from Byrsonima microphylla. Phytochemistry, v. 66, p. 2388-2392, 2005.

14. SOUZA, M. P.; MATOS, F. J. A., ALENCAR, J. W. et al. Triterpenoids of plants from Northeast Brazil Byrsonima sericea, Crataeva tapla and Curatella americana. Revista Brasileira de Farmácia v. 51, p. 67-70, 1970. 